\title{
Using Conjoint Analysis to Help Design Product Platforms
}

\author{
William L. Moore \\ David Eccles School of Business, University of Utah, Salt Lake City, Utah, USA \\ Jordan J. Louviere \\ Department of Marketing, University of Sydney, Sydney, Australia \\ Rohit Verma \\ Department of Management, DePaul University, Chicago, Illinois, USA
}

\begin{abstract}
This article illustrates how one can combine different conjoint analysis studies, each containing a core of common attributes, to help design product platforms that serve as the foundation for multiple derivative products. The illustration is based on actual, but disguised, data from a small company that makes electronic test equipment.

This article demonstrates that decisions that consider products individually are likely to be suboptimal and can be significantly different than those based on product platforms. Suboptimality can occur either when preferences for product features differ across markets or when a technology is more important to the overall company than it is to an individual product. Additionally, we show the importance of considering both fixed and variable costs when performing this type of analysis as sales, contribution, and profit-maximizing products are quite different. Finally, sensitivity analyses show that these results are robust with respect to assumptions about price sensitivity, fixed costs, and timing of entry.
\end{abstract}

\section{Introduction}

According to a recent PDMA Frontier Dialogue Session [15], product platforms are an important topic in new product development. A platform is a design, technology, or set of subsystems and interfaces shared by one or more product families [23-25]. In a well-known example, Sony introduced more than 160 variations of the Walkman from four product platforms between 1980 and 1990 [36]. Despite tools like aggregate product plans [44], composite product design [24], and metrics to measure productivity [26], the PDMA session participants concluded that many companies lack the necessary tools to take full advantage of this concept.

We illustrate how conjoint analysis can be used to help design product platforms by bringing together demand-side forecasting methods with supply-side cost estimates. We compare sales and profit-maximizing designs and show that designs most closely matching 
customer desires may lead to suboptimal profits. Additionally, we show that platform-based designs can be significantly more profitable than isolated line extensions.

Conjoint analysis has proven to be a popular way to estimate the value that consumers associate with particular product features/attributes1. Conjoint analysis allows companies to form benefit segments and make design tradeoff decisions among various features. (For recent JPIM articles on conjoint analysis, see $[4,6,30]$.)

There has been considerable interest in the use of conjoint analysis to develop optimal product configurations, i.e., designs forecast to maximize sales or profits for a given competitive setting $[5-8,19,23,38,42,43]$.

Most of these models have focused on either individual products or, if multiple products were considered, they were assumed to be independent from a technology and manufacturing standpoint. One exception is Meyer and Lehnerd [24], who discussed how Sunbeam used utility weights from separate conjoint studies in the U.S., Mexico, and France in an ad hoc manner to help design a new iron. Additionally, most of these models have focused on maximizing sales. However, Green and Krieger [6,8] demonstrated the importance of incorporating estimates of variable costs into choice simulators. They showed that attributes that have larger sales impacts might differ from those that have greater profit impacts, because those more valued by consumers also may cost more to produce.

Our illustration builds on and extends this work in two ways: (1) we provide a more formal way to combine the results of different conjoint analysis studies containing a core of common features to design product platforms and derivative products that maximize success across several markets; and (2) we incorporate estimates of both variable costs and fixed costs. We also perform sensitivity analyses on prices, fixed costs, and timing of entry. This article is distinct from, but complementary to, several articles in operations management. First, following well-cited articles by Skinner [41] and Wheelwright and Clark [44], several authors have examined the relationship among product variety, production process, and performance $[11,13,18,21,22,34,35,37]$. They found higher performance was achieved when product variety and production process were coordinated and that certain steps such as lean manufacturing may allow greater variety without a performance penalty. However, as pointed out by Skinner [41], continued addition/ change in product mix can lead to multiple operational difficulties (confusion, lack of focus, complex process flows, etc.). Whereas these articles look at the impact of product variety on the production process, they take the amount of product variety as a given and do not focus on optimal product design issues.

Second, this research is related to issues concerning commonality and the optimal amount of product proliferation faced by firms contemplating mass customization [31], Pine et al [32] report the common problem of companies giving customers more choices than they want or need. They cite examples in which Toyota found that $20 \%$ of its product varieties 
accounted for $80 \%$ of it sales and Nissan reportedly offered 87 different types of steering wheels.

Two other operations management articles are more closely related to our work. First, Morgan et al. [29] developed a theoretical approach to find a profit-maximizing set of products. Their approach differs from ours in that they assume a set of (say 20) products has already been developed, and they search for a profit-maximizing subset taking into account variable manufacturing, inventory, and setup costs. Krishnan et al [20] formulated a network model for the optimal design of a product family based on a platform and set of derivative products. Products varied along a single performance dimension, and the development cost of each derivative product was a function of adaptation and unique design costs.

Whereas these articles investigate product design and operations management issues in considerable depth, neither deals with the issues of this article-use of consumer preferences and managerial cost estimates to develop a product platform and derivatives.

\section{Product Platform}

Most companies are engaged in multiple development projects, but manage them individually. This can result in redundant efforts and loss of consistency and focus. However, focusing on product platforms can reduce these problems [23].

A platform is a foundation for a range of individual product variations; i.e., something that is developed once and used in multiple applications [15]. For example, Canon developed a laser printer engine used in a number of printers, scanners, fax machines, and copiers. Similarly, Toyota plans to launch five new made-in-America cars from its 1997 Camry platform [1]. Procter and Gamble developed Liquid Ariel for Europe, Liquid Tide for the U.S., and Liquid Cheer for Japan from a common set of building blocks [2]. Intel concentrates on each new microprocessor generation, then develops a coherent set of derivative products (e.g., faster clock speeds; enhancements like MMX or speed doubler technology; and lower power consumption chips for portables). Meyer et al [26] found that follow-on products in one company often had engineering costs only $10 \%$ as high as platform products. Ford is trying to save $\$ 3$ billion annually by reducing the number of platforms it develops.

Organizing product planning around product platforms can:

1. Focus greater management attention on these decisions that have a disproportionate impact on costs and performance of subsequent products;

2. Increase the odds of investing a sufficient amount in leveragable core capabilities;

3. Minimize product confusion and overlap;

4. Save engineering, manufacturing, and purchasing costs;

5. Minimize manufacturing complexity while retaining a variety of customer choices; and

6. Speed derivative products to market. 
However, the tradeoff of saving money through commonality versus increasing sales by tailoring products is complex, as seen in two recent examples. The 1991 Honda Accord sold well in the U.S., but poorly in Japan due to its conservative styling. Ford's 1995 Mondeo sold well in Europe, but its U.S. counterpart, the Contour, sold poorly, partly due to high price and limited back seat space.

\section{Empirical Illustration}

\section{Background and Data Collection}

Company and products. We deal with two products made by a small company, "Alpha," which is a leader in several niches of the electronic test equipment market. Its customer list includes leading electronic equipment manufacturers like IBM, HP, and 3M. It might be likened to one of Simon's hidden champions [40].

The two products, " $\mathrm{X}$ " and " $\mathrm{Z}$," cost several thousand dollars, and industry sales for each is under 1,000 units annually. They compete in separate markets. $X$ costs more to produce and is priced several times higher than Z. They share a common technological platform, but each product also has several unique features.

Customer utilities. A different questionnaire was developed for each product. Questionnaires were faxed to individuals who play a key role in the purchase decision for this type of equipment. These names were drawn from a list of companies that constitute approximately $80 \%$ of the market. A fractional factorial design was used to create 16 hypothetical testers for the conjoint part of the study. Some levels of certain features cost significantly more to produce. These levels were associated with an increment added to the base price; hence, their utility weight represents a preference for that feature at the higher price.

Respondents rated their likelihood of purchasing each tester. Individual-level utilities for feature levels were estimated from these likelihood ratings. See the Appendix for some technical details of our approach. Levels and average utilities of the features are given in Table 1 and described following.

The first seven features were common to both surveys. Because Alpha is the dominant supplier, respondents named another supplier from whom they also would consider purchasing and thought of it when the brand "other preferred supplier" was listed. The utility (or preference) for Alpha is higher than for "other" for both products (.462 versus - .462 for X and .032 versus -.032 for $\mathrm{Z}$ ).

The first three displays are line displays containing varying numbers of lines and characters per line. The fourth is a programmable graphics display. The current display is the least preferred, and the graphics display is the most preferred. There is a small preference for a backlight that improves visibility in poor lighting. 


\begin{tabular}{|c|c|c|c|c|}
\hline Attribute & Level 1 & Level 2 & Level 3 & Level 4 \\
\hline Brand & Alpha & Other & & \\
\hline Product X & .462 & -.462 & & \\
\hline Product Z & .032 & -.032 & & \\
\hline Display & Current Display & Larger Line Display & Largest Line Display & Graphic Display \\
\hline Product X & -.356 & .091 & -.166 & .431 \\
\hline Product $\mathrm{Z}$ & -.319 & .138 & .008 & .173 \\
\hline Backlight & Yes & No & & \\
\hline Product X & .039 & -.039 & & \\
\hline Product Z & .015 & -.015 & & \\
\hline Data I/O Method & Connect to Single PC & Floppy Disk & Memory Module & Networking Capability \\
\hline Product X & -.206 & -.283 & .123 & .366 \\
\hline Product $\mathrm{Z}$ & -.036 & -.255 & -.055 & .316 \\
\hline Accuracy & Current & More Accurate & & \\
\hline Product X & -.103 & .103 & & \\
\hline Product Z & -.062 & .062 & & \\
\hline Speed & Current & Faster & & \\
\hline Product $\mathrm{X}$ & -.246 & .246 & & \\
\hline Product Z & -.136 & .136 & & \\
\hline Connection Method & Method One & Method Two & & \\
\hline Product X & .433 & -.433 & & \\
\hline Product Z & .357 & -.357 & & \\
\hline \multicolumn{5}{|l|}{ Stress Level Applied } \\
\hline (Product X Only) & Current & Higher & & \\
\hline Product X & -.052 & .052 & & \\
\hline \multicolumn{5}{|l|}{ Maximum Size Tested } \\
\hline (Product Z Only) & Current & Larger & & \\
\hline Product Z & .076 & -.076 & & \\
\hline Price (\% of current) & $84 \%$ & $92 \%$ & $100 \%$ & $108 \%$ \\
\hline Product X & .028 & .001 & -.001 & -.028 \\
\hline Product $\mathrm{Z}$ & .085 & .029 & -.029 & -.085 \\
\hline
\end{tabular}

Table 1. Tester Attribute Levels and Utility Weights

Information must be input to test different components and output for statistical process control. There are four Data I/O Methods: (1) connection to a personal computer, (2) connection to a network, (3) a floppy disk drive, or (4) a memory module (such as a PCMCIA card). Networking capability is preferred.

Speed and accuracy were specified in technical terms, but disguised here. Customers preferred faster and more accurate testers. There are two primary methods of connecting the tester to the item being tested. Alpha pioneered method one, which is greatly preferred to method two.

Finally, the last two features differed between product lines. Product $X$ can differ in terms of the level of stress force that can be applied to the item under test and product $Z$ can differ in the maximum size of the item that could be tested. The ability to apply higher levels of stress force is preferred, but the current maximum size is satisfactory. The survey used dollar prices, but we express price in terms of deviations from current price.

The estimated utility weights make intuitive sense as brand Alpha, its method of connection, better displays, faster, more accurate, and less expensive testers are preferred.

Product costs. A team of engineers and top managers estimated both variable 
(component purchase prices) and fixed (engineering) costs for each level of each feature. For example, the primary cost difference among the three line displays is in the purchase price due to size differences. However, a graphics display entails both a fixed engineering cost associated with software development and the variable cost of the purchased display.

Market simulations. Individual consumer utility estimates were combined with managerial judgments concerning market size and a likely future competitive set for each market, as well as fixed and variable cost estimates, and input to a Fortran program that searched for the optimal product configuration through complete enumeration. For each combination of product features, the program forecast which tester each person would buy. These were summed to forecast industry sales, market shares, contribution, and profit.

\section{Optimal Products}

First, we consider optimal product designs for $X, Z$, and a common platform. Then, we examine price and cost sensitivities, the impact of time of entry, and an optimal level of product proliferation.

Product X. After providing a more detailed analysis of Product $X$ to illustrate our procedure, we present brief analyses of Product $Z$ and the platform. Table 2 presents the new

Market Share-Maximizing Combinations

Description of New Product

\begin{tabular}{|c|c|c|c|c|c|c|c|}
\hline \multirow[b]{2}{*}{ Mkt Share } & \multirow[b]{2}{*}{ Contrib $(\%)^{a}$} & \multirow[b]{2}{*}{ Profit $(\%)^{b}$} & \\
\hline & & & Backlight & I/O Method & Accuracy & Stress Level & Price $(\%)^{c}$ \\
\hline 89.8 & 64.8 & -329.1 & Yes & NW & Current & Current & $84 \%$ \\
\hline 89.3 & 63.9 & -595.5 & Yes & NW & More & Current & $84 \%$ \\
\hline 88.9 & 64.9 & -340.1 & No & NW & Current & Current & $84 \%$ \\
\hline 88.3 & 63.3 & -607.7 & No & NW & More & Current & $84 \%$ \\
\hline
\end{tabular}

Contribution-Maximizing Combinations

\begin{tabular}{|c|c|c|c|c|c|c|c|}
\hline \multirow[b]{2}{*}{ Mkt Share } & \multirow[b]{2}{*}{ Contrib $(\%)$} & \multirow[b]{2}{*}{ Profit $(\%)$} & \multicolumn{5}{|c|}{ Description of New Product } \\
\hline & & & Backlight & I/O Method & Accuracy & Stress Level & Price $(\%)$ \\
\hline 85.9 & 100.0 & 94.5 & Yes & NW & Current & Higher & $108 \%$ \\
\hline 86.2 & 99.6 & -155.0 & Yes & NW & More & Higher & $108 \%$ \\
\hline 85.1 & 98.6 & -179.7 & No & NW & More & Higher & $108 \%$ \\
\hline 83.8 & 97.6 & 41.2 & No & NW & Current & Higher & $108 \%$ \\
\hline
\end{tabular}

Profit-Maximizing Combinations

\begin{tabular}{|c|c|c|c|c|c|c|c|}
\hline \multirow[b]{3}{*}{ Mkt Share } & \multirow[b]{3}{*}{ Contrib $(\%)$} & \multirow[b]{3}{*}{ Profit $(\%)$} & \multicolumn{5}{|c|}{ rofit-Maximizing Combinations } \\
\hline & & & \multicolumn{5}{|c|}{ Description of New Product } \\
\hline & & & Backlight & I/O Method & Accuracy & Stress Level & Price $(\%)$ \\
\hline 80.6 & 76.6 & 100.0 & No & $\mathrm{PC}$ & Current & Current & $108 \%$ \\
\hline 85.9 & 100.0 & 94.5 & Yes & NW & Current & Higher & $108 \%$ \\
\hline 79.4 & 75.3 & 72.0 & Yes & PC & Current & Current & $108 \%$ \\
\hline 84.8 & 74.3 & 50.0 & No & $\mathrm{PC}$ & Current & Current & $100 \%$ \\
\hline
\end{tabular}

\footnotetext{
${ }^{a}$ As a percent of the contribution-maximizing configuration-see the first configuration under Contribution-Maximizing Combinations.

${ }^{b}$ As a percent of the profit-maximizing configuration-see the first configuration under Profit-Maximizing Combinations. Negative numbers indicate that engineering costs would not be recouped in the first 3 years of sales.

${ }^{c}$ As a percent of current price.
}

Table 2. Optimal Product Configurations for Product $X$ 
Product $X$ designs forecast to provide the highest market share, contribution (volume times price minus variable cost), and profit (contribution minus fixed engineering costs) over a 3-year period. In order to disguise the results, both contribution and profits are reported as a percent of the configuration that maximizes each respective criterion.

The four highest-ranking products on each criterion are presented to show feature commonality. The highest-ranking products on all three criteria have graphics displays, faster speed, and connection method one. Therefore, these features are not displayed.

The market share-maximizing products indicate the most preferred feature combinations. In addition to graphics displays, faster speeds, and connection method one, all sales-maximizing products have networking capability, current stress levels, and are priced at $84 \%$ of current price. Backlight and accuracy have little impact on market share. In spite of very high market shares, low prices lead to low contribution and negative profits.

The next four products maximize contribution before fixed engineering costs. They consider not only which features are most valued, but also the variable costs of providing them. Like the market share-maximizing testers, they have networking capability. However, in contrast, they offer the ability to apply higher stress levels and have prices $8 \%$ higher than current; in both cases, slightly lower volumes are more than offset by higher margins. As before, neither backlight nor accuracy has a big impact on contribution. Compared to the salesmaximizing testers, market share drops slightly, but contribution increases by about $50 \%$.

The final four testers maximize profits. Like the contribution-maximizing testers, these have higher prices. However, in contrast, most of the profit-maximizing testers do not have networking capability, ability to apply higher stress levels, nor a higher level of accuracy.

A comparison of the profit, contribution, and sales- maximizing testers shows that the optimal product differs substantially depending upon what is being maximized. Whereas Alpha wants to maximize profits, sale-maximizing configurations indicate what is most desired by customers and where possible competitive openings exist. Contribution-maximizing configurations focus on easier-to-estimate variable costs and provide maximum profit under an assumption of zero fixed costs. Differences between contribution and profit-maximizing configurations point to places where one might try to reduce fixed costs.

All three criteria suggest that the tester should have a graphics display, faster speed, connection method one, and current level of accuracy. There is some question about the following four features:

1. Only part of the market needs a backlight, but it is relatively inexpensive to provide.

2. Most customers want networking capability and it provides a good margin, but engineering costs are high.

3. Similarly, increasing the stress level provides good margins, but has high engineering costs. However, only part of the market needs this capability. 
4. Higher prices maximize contribution and profit, but leave a possible entry path for competitors.

Decisions about these features will be revisited in subsequent analysis. However, the profitmaximizing Product $X$ is used as a basis of comparison in Table 3 (financial results are in the top rows and product characteristics in the bottom rows).

Product Z. A similar analysis of Product Z was undertaken. The first two columns of Table 3 show that the profit-maximizing $X$ and $Z$ products are quite similar: graphics display, connection to a single PC for data I/O, current level of accuracy, faster speed, connection method one, and price $8 \%$ higher than current. The only difference in common attributes is that the optimal product $Z$ has a backlight. Second, every product $Z$ configuration is unprofitable when it has to

\begin{tabular}{|c|c|c|c|c|}
\hline & \multicolumn{3}{|c|}{ Independent Decisions } & \multirow{2}{*}{$\frac{\text { Platform Decision }}{\text { Platform }}$} \\
\hline & Product X & Product $\mathrm{Z}$ & Product X First & \\
\hline \multicolumn{5}{|l|}{ Forecast Results } \\
\hline Market share & 80.6 & 59.0 & $80.6 / 59.0^{a}$ & $85.9 / 69.9$ \\
\hline Contribution (\%) & $76.6 \%$ & $25.3 \%$ & $101.8 \%$ & $129.6 \%$ \\
\hline Profit $(\%)$ & $100.0 \%$ & $-1052.2 \%$ & $401.7 \%$ & $578.6 \%$ \\
\hline Decision & Launch & Don't launch & Launch & Launch \\
\hline \multicolumn{5}{|l|}{ Product Characteristics } \\
\hline \multicolumn{5}{|l|}{ Platform } \\
\hline Brand & Alpha & Alpha & Alpha & Alpha \\
\hline Display & Graphics & Graphics & Graphics & Graphics \\
\hline Backlight & No & Yes & No & Yes \\
\hline I/O method & Connect to PC & Connect to $\mathrm{PC}$ & Connect to $\mathrm{PC}$ & Networked \\
\hline Accuracy & Current & Current & Current & Current \\
\hline Speed & Faster & Faster & Faster & Faster \\
\hline Connection method & Method one & Method one & Method one & Method one \\
\hline \multicolumn{5}{|l|}{ Other } \\
\hline Stress level & Current & NA & Current & Higher \\
\hline Max size & NA & Current & Current & Current \\
\hline Price & $108 \%$ & $108 \%$ & $108 \% / 108 \%$ & $108 \% / 108 \%$ \\
\hline
\end{tabular}

${ }^{a}$ When two numbers are separated by a slash, the first refers to product $\mathrm{X}$ and the second to product $\mathrm{Z}$.

Table 3. Comparison of Decisions

bear all engineering costs. Thus, if $Z$ is the only product considered, the optimal decision would be to not develop any product.

Independent designs. Column three assumes that Products $\mathrm{X}$ and $\mathrm{Z}$ are designed independently, but fixed costs are shared where possible. Again, the only difference in common attributes between the two testers is the backlight. Neither product has networking capability. The two products generate a total expected profit that is four times higher than if $X$ is the only product launched. Even though this is not the optimal platform, it shows the impact of spreading fixed costs over two product lines.

Product platforms. Finally, a common platform consisting of display, presence of backlight, data I/O method, accuracy, speed, and connection method is examined (column four). When the platform is optimized over two products simultaneously, it contains a 
backlight, networking capability, and the ability to apply higher stress levels. Furthermore, the expected profit is almost six times that of product $X$ alone and almost $50 \%$ above that generated from independent designs and shared costs.

Summary. So far, we have tried to demonstrate: (1) the ease of using conjoint-based optimal design procedures to develop platforms for multiple markets; (2) the need to consider fixed and variable costs when determining optimal designs; and (3) that considering products individually can be suboptimal. Furthermore, the platform analysis helped resolve the first three feature questions - those involving backlight, networking capability, and maximum stress level that can be applied.

We now return to the question of optimal price. Figure $1 \mathrm{~A}$ shows that reducing prices from $108 \%$ of current price to $84 \%$ increases the market share of $X$ and $Z$ by 1.3 and 11 points, respectively. Optimal profits (100\% - profit percent is measured on the same vertical scale as market share) occur when both products are priced at $108 \%$ of current price. If only the price of $Z$ is reduced, profits fall by $28 \%$; if only $X$ 's price is reduced, profits fall by two thirds; and if the price of both products is reduced, profits fall almost to zero.

Because it is possible that people are less price sensitive when filling out a questionnaire than when making decisions with real financial implications, this analysis is repeated in Figure IB under the assumption that each buyer is twice as price sensitive as indicated by the conjoint analysis. Comparing Figures $1 \mathrm{~A}$ and $1 \mathrm{~B}$ at the price of $108 \%$ of current, greater price sensitivity results in decreased market shares of $2.6 \%$ and $14.2 \%$, for $X$ and $Z$, respectively, and a profit decrease of over $35 \%$. With greater price sensitivity, the profit-maximizing price of $Z$ is the same as current, not $8 \%$ higher. Additionally, Figure IB shows that even with greater price sensitivity, profits drop substantially when price is reduced because $X$ gains very little in volume. Whereas greater price sensitivity reduces profits and changes the profit-maximizing price of $Z$, it does not alter the decision about the optimal platform features.

\section{Product Options - Mass Customization}

In the analysis to date, only a single product in each product line has been examined. However, it may be better to offer different products to segments desiring different features. Figure 2 shows the impact of offering customers a choice of certain features. For example, the first two bars show that if customers are offered the choice of a model with or without a backlight, sales would increase by $2 \%$ and profits would increase by $12 \%$. The most profitable single option is offering both a connection to a single PC and networking capability (which increases profits by $30 \%$ ). Whereas this figure shows the impact of individual options for simplicity of exposition, it could easily be expanded to cover multiple combinations. However, this analysis does not reflect the impact of potential operational problems. Strategic and operational issues suggest that rather than offering complete mass customization and too many choices, faster test speed, networking capability, and backlight should be the only options. 


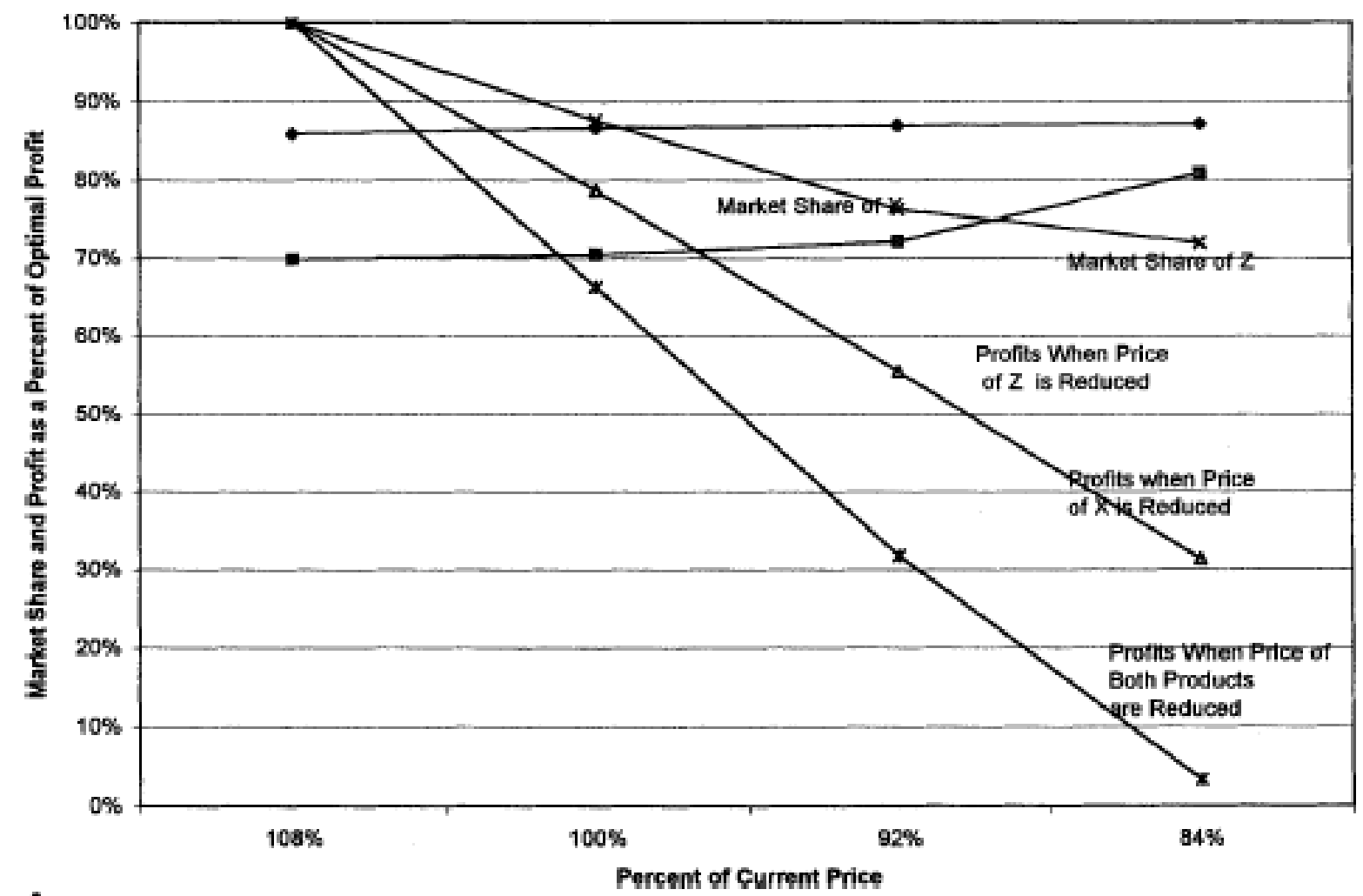

A

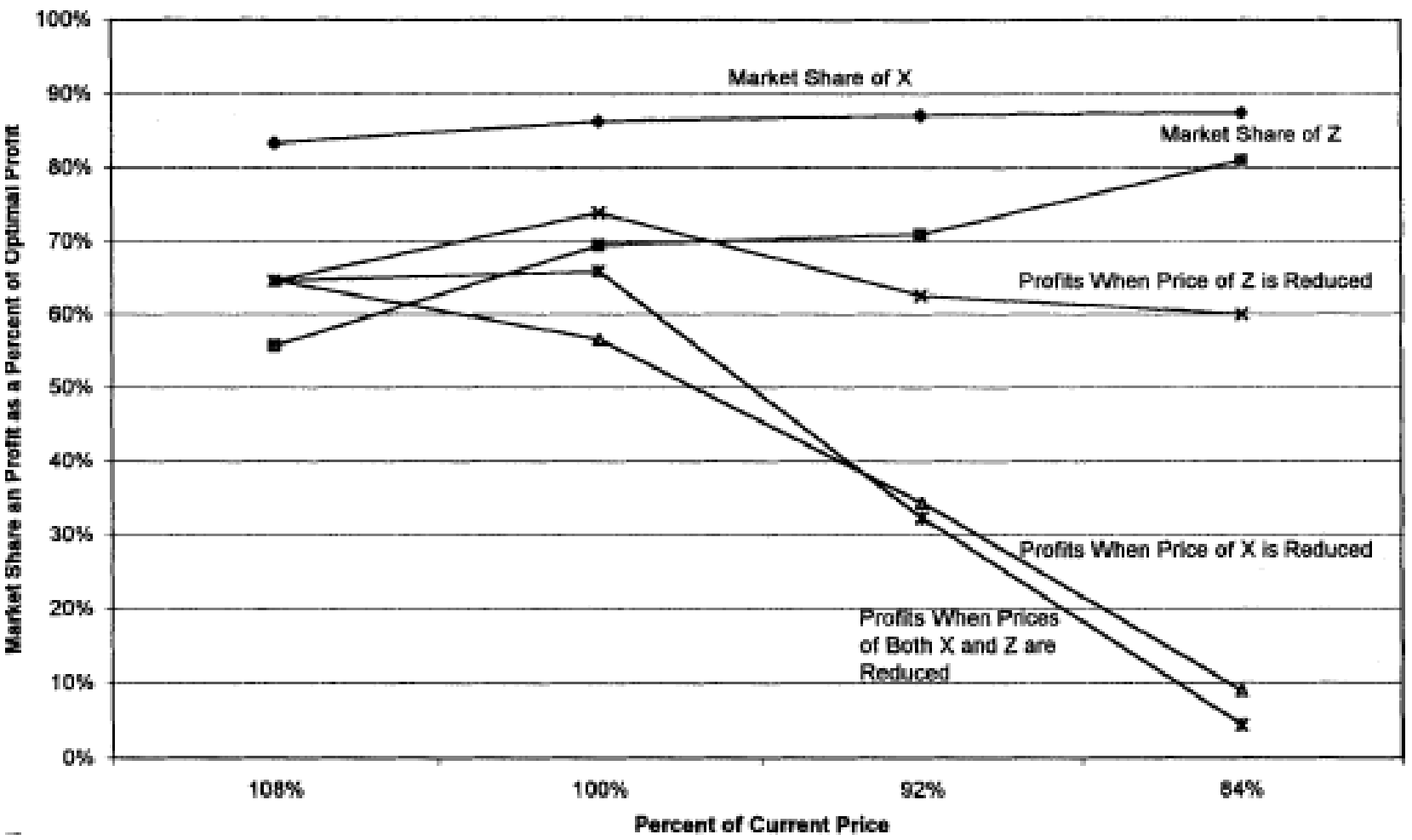

Figure 1. Impact of reducing prices. (A) Estimated price sensitivity. (B) Twice as price sensitivity as estimated 


\section{$\underline{\text { Fixed-Cost Sensitivity Analyses }}$}

Because fixed costs may be estimated with less accuracy than variable costs, two steps were taken. First, engineering time estimates were made very conservatively-initial estimates were multiplied by 1.5 . Second, sensitivity analyses on engineering time were run. As long as engineering time is between $45 \%$ and $180 \%$ of the estimated time, the optimal product platform remains the same. If engineering time is $<45 \%$ of estimated, product $X$ remains the same, but it is more profitable to increase the maximum size of item that $Z$ can test. If engineering time is between $180 \%$ and $225 \%$ of estimated, the current (rather than higher) level of stress that can be applied by product $X$ becomes the optimal level. If engineering time is $>225 \%$ of estimated, then Alpha is better off not redesigning at this point.

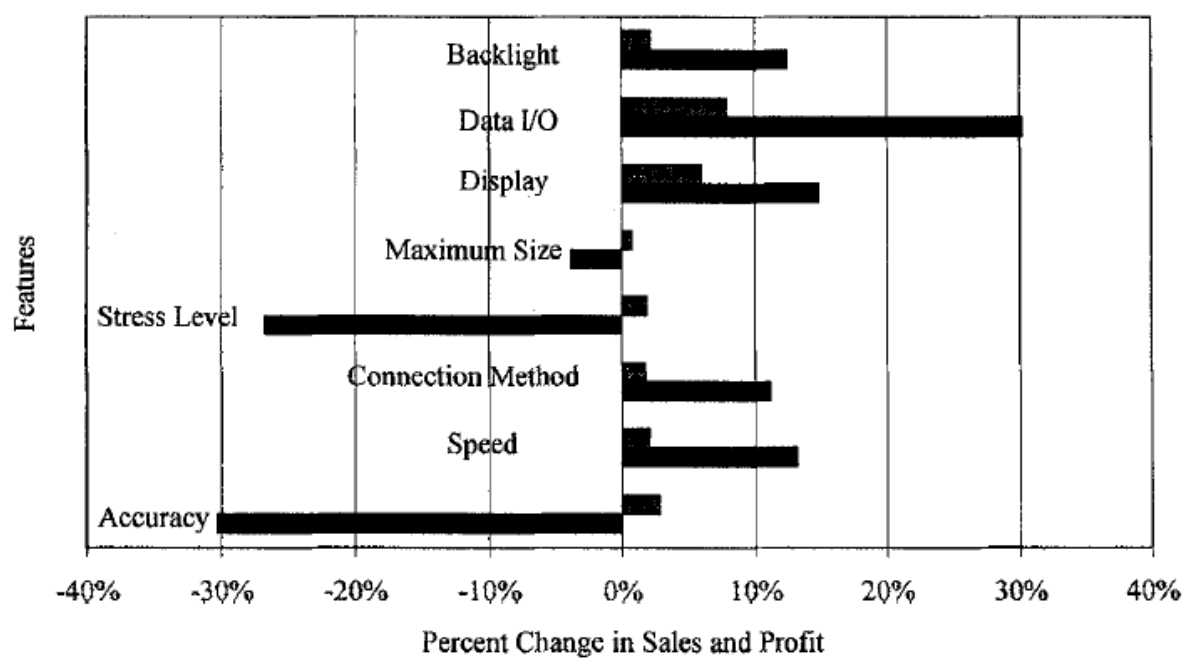

Profits Sales

Figure 2. Impact of making features optimal.

\section{Timing of Entry}

In addition to generating better designs, platforms also can result in faster new product introductions. The next analysis considers the relative importance of these two benefits. In Table 3, it was seen that the impact of the optimal platform over independent products was a $50 \%$ increase in profit. Here, we contrast the impact of optimal portfolio with that of timing. We assume (1) one of two sets of products-either the optimal platform or the optimal individual products of Table 3, (2) that the product life cycle would last for 4 years after the first product was introduced, (3) a 10\% cost of capital, and (4) one of two timing of entry strategies - simultaneous or a 1-year lag on product Z (which would give it a 3-year product life).

The optimal platform launched simultaneously produced the largest net present value (NPV). Introducing the optimal platform with a 1-year lag for Z reduced the optimal NPV by $12 \%$. Introducing the optimal individual products simultaneously reduced the optimal NPV by 
$24 \%$, and introducing optimal individual products with a year lag for Z reduced optimal NPV by $33 \%$. In this case, optimal portfolio had a greater impact on NPV than did timing; however, this will obviously differ by situation [3].

Several competitive analyses also could be conducted. One might investigate the impact of other competitive sets. Specifically, one might assume a cost structure and search for optimal competitive products. Finally, one might use a game-theoretical approach to forecast possible moves [4].

\section{Conclusion}

\section{Product Platforms}

Whereas conjoint analysis-based optimal product design models have been used to design individual products, we demonstrated that they also can be used to design product platforms. More than just spreading fixed costs, the greatest benefits were gained when products were planned jointly. Here, each market was surveyed with a different questionnaire, but the questionnaires contained some common features in order to determine their impact across both markets. Sales, contribution, and profits provide common, non-political, metrics to assess the impacts of these decisions across multiple product lines.

Table 3 demonstrates the impact of making a product design decision based on a platform versus independent decisions about each product. It shows that Product $Z$ would not be launched if it is the only one. Second, if the products are designed independently but share fixed costs, the optimal Product $X$ would not have a backlight, networking capability, or the ability to apply higher stress levels. Whereas this combination generates higher profit than either product alone, a platform based on both products simultaneously would contain those features and increase expected profits by almost 50\%. Figure 2 indicates that it is possible to increase this profit further by making some features optional, such as backlight and networking capability. Other analyses show these results are relatively robust to assumptions about price sensitivity and fixed costs. Furthermore, in this case, product design decisions have a bigger profit impact than timing benefits.

Considering products independently resulted in sub- optimal decisions in two cases. First, they occurred when engineering costs (for items like networking capability) were high enough to be unprofitable when applied to a single product line, but were profitable when shared across multiple products. Platforms improve decisions when a technology or feature is more valuable to the entire organization than to an individual product line.

They also occurred when preferences differed across the products. Here, preferences for a backlight differed across the two customer groups. If product $X$ was considered alone, the profit-maximizing configuration would not include a backlight. However, preference for this feature among customers of product $Z$ was strong enough to make sense to offer it. Whereas there were only small intersegment preference differences in this situation, they can be more 
important in other situations (like the automobile examples). This approach provides a straightforward way of resolving such disputes among multiple products.

Furthermore, the decision about networking had a secondary effect on maximum stress level that could be applied. When the tester had a connection to a PC, current stress level maximized profit, but with networking capability, the higher stress level was optimal (see the first two profit-maximizing testers in Table 2).

\section{Conjoint Analysis}

We found significant value in comparing designs that maximize different criteria (e.g., unit sales, contribution, and profits). Differences between sales and profit-maximizing configurations were sufficiently large that it is prudent to use even rough cost estimates and sensitivity analyses. Even if one is interested in maximizing profits, sales-maximizing designs show what features are most desired. Contribution-maximizing configurations indicate what is optimal when fixed costs could be reduced significantly.

We also found that it was good to examine more than just the optimal product configuration for any criterion. Errors in preference and cost estimates mean that the first several configurations on any dimension (profits, contribution, or sales) may be equally good. Additionally, patterns in the top-performing configurations provide additional insights, e.g., one would have more confidence choosing features that are in all top configurations than features in only one top configuration.

Looking at multiple objective functions, multiple configurations for each objective, and sensitivity analyses complicates the analysis. However, we feel the additional insights are worth the effort.

\section{References}

1. Armstrong, Larry and Naughton, Keith. The new Camry's one-two punch. Business Week September 16, 1996.

2. Bartlett, Christopher A. and Ghoshal, Sumantra. Managing Across Borders: The Transnational Solution. Boston: Harvard Business School Press, 1991.

3. Bayus, Barry L. Speed-to-market and new product performance tradeoffs. Journal of Product Innovation Management 14:485M97 (1997).

4. Choi, S. Chan and DeSarbo, Wayne S. A conjoint-based product designing procedure for incorporating price competition. Journal of Product Innovation Management 11:451-459 (1994).

5. Green, Paul E. and Krieger, Abba M. Recent contributions to optimal product positioning and buyer segmentation. European Journal of Operational Research 41:127-141 (1989). 
6. Green, Paul E. and Krieger, Abba M. Product design strategies for target-market positioning. Journal of Product Innovation Management 8:189-202 (1991).

7. Green, Paul E. and Krieger, Abba M. Segmenting markets with conjoint analysis. Journal of Marketing 55:20-31 (1991).

8. Green, Paul E. and Krieger, Abba M. Conjoint analysis with productpositioning applications. In: Handbooks in OR \& MS, Vol. 5. J. Eliashberg and G. L. Lilien (eds.). Elsevier Science Publishers, 1993, pp. 467-513.

9. Green, Paul E. and Krieger, Abba M, Individualized hybrid models for conjoint analysis. Management Science 42:850-867 (1996).

10. Green, Paul E. and Srinivasan, V. Conjoint analysis in marketing: New developments with implications for research and practice. Journal of Marketing 54:3-19 (1990).

11. Hayes, Robert H. and Wheelwright, Steven C. Link manufacturing process and product life cycles. Harvard Business Review January- February, 57:133-140 (1979).

12. Johnson, Richard M. Adaptive conjoint analysis. In: Proceedings of the Sawtooth Software Conference on Perceptual Mapping, Conjoint Analysis, and Computer Interviewing. Sun Valley, ID: Sawtooth Software, March 1987, pp. 253-266.

13. Jordan, W.C. and Graves, S.C. Principles on the benefits of manufacturing process flexibility. Management Science 41:577-594 (1995).

14. Lenk, Peter J., DeSarbo, Wayne S., Green, Paul E. and Young, Martin R. Hierarchical Bayes conjoint analysis: Recovery of partworth heterogeneity from reduced experimental designs. Marketing Science 15:173-191 (1996).

15. Liebe, John H. Spring Frontier dialogue: Special interest group on platform planning techniques. Visions 20:10-11 (1996).

16. Louviere, Jordan J. Analyzing Decision Making: Metric Conjoint Analysis. Newbury Park, CA: Sage Publications, 1988.

17. Louviere, Jordan J. and Woodworth, George. Design and analysis of simulated consumer choice or allocation experiments: An approach based on aggregate data. Journal of Marketing Research 20:350-367 (1983).

18. Karmarker, U.S. and Pitbladdo, R.C. Quality class and competition. Management Science 43:27-39 (1997).

19. Kohli, R. and Krishnamurti, R. A heuristic approach to product design. Management Science 33:1523-1533 (1983). 
20. Krishnan, Viswanathan, Singh, Rahul and Tirupati, Devanath. A Model-Based Approach for Planning and Developing a Family of Technology-Based Products. Working paper, Department of Management, University of Texas, December 1996.

21. Lee H.L. and Tang, C.S. Modeling the costs and benefits of delayed product differentiation. Management Science 43:40-53 (1997).

22. MacDuffie, J.P., Sethuraman, K. and Fisher, M.L. Product variety and manufacturing performance: Evidence from the International Automotive Assembly Plant study. Management Science 42:350-369 (1996).

23. McGrath, Michael E. Product Strategy for High-Technology Companies: How to Achieve Growth, Competitive Advantage, and Increased Profits. Burr Ridge, IL: Irwin Professional Publishing, 1995.

24. Meyer, Marc H. and Lehnerd, Alvin P. The Power of Product Platforms: Building Value and Cost Leadership. New York: Free Press, 1997.

25. Meyer, Marc H. and Utterback, James M. The product family and the dynamics of core capability. Sloan Management Review 34:29-47 (1993).

26. Meyer, Marc H., Tertzakian, Peter and Utterback, James M. Metrics for managing research and development in the context of the product family. Management Science 43:88-111 (1997).

27. Moore, William L., Gray-Lee, Jason and Louviere, Jordan J. A crossvalidity comparison of conjoint analysis and choice models at different levels of aggregation. Marketing Letters 9:195-208 (1998) In press.

28. Moore, William L., Pessemier, Edgar A. and Little, Taylor E. Predicting brand choice behavior: A marketing application of the Schone- mann and Wang unfolding model. Journal of Marketing Research 16:203-210 (1979).

29. Olin Morgan, Leslie, Daniels, Richard L. and Kouvelis, Panos. Mar-keting/Manufacturing Tradeoffs in Product Line Management: Insights from a Mathematical Programming Model. Working paper, David Eccles School of Business, University of Utah, October 1996.

30. Page, Albert L. and Rosenbaum, Harold F. Redesigning product lines with conjoint analysis, how Sunbeam does it. Journal of Product Innovation Management 4:120-137 (1987).

31. Pine, Joseph B., II. Mass Customization: The New Frontier in Business Competition. Boston: Harvard Business School Press, 1993.

32. Pine, Joseph B., II, Victor, Bart and Boyington, Andrew C. Making mass customization work. Harvard Business Review 71:108-121 (1993). 
33. Pessemier, Edgar A., Burger, Philip, Teach, Richard and Tigert, Douglas. Using laboratory brand preference scales to predict consumer brand purchases. Management Science 17:371-385 (1971).

34. Raman, N. and Chhajed, D. Simultaneous determination of product attributes and prices, and production processes in product line design. Journal of Operations Management 12:187-204 (1995).

35. Safizadeh, M.H., Ritzman, L.P., Sharma, D. and Wood, C. An empirical analysis of productprocess matrix. Management Science 42: 1576-1591 (1996).

36. Sanderson, S. and Uzumeri, V. Cost models for evaluating virtual design strategies in multicycle product families. Journal of Engineering and Technology Management. Also Rensselaer Polytechnic Institute, Center for Science and Technology Policy, Troy, NY, 1991.

37. Schiller, Zachary, Burns, Greg and Lowry Miller, Karen. Make it simple. Business Week September 9, 1996.

38. Sen, Subrata K. Issues in optimal product design. In: Analytical Approaches to Product and Market Planning: The Second Conference. Cambridge MA, The Marketing Science Institute, 1982, pp. 365-374.

39. Silk, Alvin J. and Urban, Glen L. Pretest market evaluation of new package goods: A model and measurement method. Journal of Marketing Research 15:171-191 (1978).

40. Simon, Hermann. Hidden Champions: Lessons from 500 of the World's Best Unknown Companies. Boston: Harvard Business School Press, 1996.

41. Skinner, W. The focused factory. Harvard Business Review May-June: 113-121 (1974).

42. Sudharshan, D., May, J.H. and Gruca, Thomas. DIFSTRAT: An analytical procedure for generating optimal new product concepts for a differentiated-type strategy. European Journal of Operational Research 36:50-65 (1988).

43. Sudharshan, D., May, J.H. and Shocker, Allan. A simulation comparison of methods for new product location. Marketing Science 6:182- 202 (1987).

44. Wheelwright, Steven C. and Clark, Kim B. Revolutionizing Product Development: Quantum Leaps in Speed, Efficiency, and Quality. New York: Free Press, 1992. 


\section{Appendix}

The focus of this article is on a managerial application of conjoint analysis to design optimal products. The purpose of this Appendix is to provide some of technical details. Optimal product design models maximize a form of the following general function:

$$
\text { Profit }_{i}=S * M S_{i}\left(P R_{i}-V C_{i}\right)-F C_{i}
$$

where $S$ is the size of the market, $\operatorname{Profit}_{i}, M S_{i}, P R_{i}, V C_{i}$, and $F C_{i}$, are the profit, market share, price, variable cost, and fixed cost for product $i$, respectively. This equation can maximize contribution, dollar sales volume, or unit sales volume by sequentially setting $F C_{i}, V C_{i}$, and $P R_{i}$ equal to 0,0 , and 1 . Changes in the size of the market, $S$, will not change the contribution or sales-maximizing combination. However, it may impact the profit- maximizing configuration due to fixed costs.

When cash flows are reasonably "well behaved" (e.g., negative at first then continuously positive), the simple function in Equation 1 can be used with appropriate assumptions to find profit or cash flow-maximizing product designs. Specifically, the size of the market can be set equal to the discounted size of the market over the life of the product. Alternatively, it can be modified to incorporate both the time value of money and variations in cash flow by period. In this case, the net present value of the $i$ th product, $N P V_{i}$, can be evaluated as follows:

$$
N P V_{i}=\sum_{t=0}^{T}\left(\frac{1}{1+r}\right)^{t} *\left(S_{t} * M S_{i t}\left(P R_{i t}-V C_{i t}\right)-F C_{i t}\right.
$$

Here, a discount factor $r$ has been added and all terms now have time subscripts. This additional complexity would be especially important for products with long life cycles.

Product $i$ 's profit is a function of its features. Let $X_{i}$, be a zero-one vector indicating the presence or absence of each level of each attribute for product $I .{ }^{1}$ Let $P, V$, and $F$ be vectors containing the price, variable, and fixed costs of each level of each attribute, respectively. $P R_{i}$, $\left.V C_{i}\right)$, and $F C_{i}$, are obtained by multiplying $P, V$, or $F$ times $X_{i}$, e.g., $P r_{i}=X_{i}{ }^{\prime} P$.

$M s_{j}$ is the sum over $J(j=1, \ldots, J)$ people of the probability that person $j$ chooses product $I, P C_{i j}$.

$$
M S_{i}=\sum_{j} P C_{i j}=\sum_{j}\left(e^{\alpha \widehat{u}_{i j}} / \sum_{i^{\prime} \in S} e^{\alpha \widehat{u}_{i \prime j}}\right) .
$$

The probability that person $\mathrm{j}$ chooses product $\mathrm{i}$ is a function of the attractiveness of product $i$, $\exp \left(\alpha \hat{u}_{i j}\right)$, divided by the sum of the attractiveness of all products in the market. This formulation is a powered BTL (Bradley-Terry-Luce) model with a scaling factor of $\alpha$. A powered

\footnotetext{
${ }^{1}$ We assumed no interactions among attributes. This was judged to be reasonable by management, and it represented a design tradeoff among numbers of attributes, levels, and the number of profiles to be evaluated by each respondent.
} 
BTL model was used because in many cases unpowered BTL models, (i.e., ones with $\alpha=1$ ) underpredict popular choices and overpredict less popular choices $[6-8,28,33,39]$. The constant $\alpha$ was estimated from two choice sets that were part of the questionnaire. An $\alpha$ was chosen so that the sum of the predicted individual choices most closely matched the actual choice shares over two sets.

The utility of the $i$ th product to person $j, u_{i j}$, is modeled as a linear function of the preferences (or utilities) of the levels of product $I$.

$$
\hat{u}_{i j}=\sum_{1} \hat{\beta}_{i j} x_{i j}
$$

There are a number of ways of estimating these utility weights, $\beta_{i j}$. These include full-profile conjoint analysis [10], ACA [12], hybrid conjoint analysis [9], and experimental choice analysis, or choice-based conjoint analysis [17].

In this application, we estimated individual-level utilities from the likelihood of purchase ratings with a logit regression using a hierarchical Bayes procedure [14]:

$$
\ln \left(r_{i j} /\left(100-r_{i j}\right)\right)=\sum_{l} \hat{\beta}_{l j} x_{i l}+\varepsilon_{i j}=\hat{u}_{i j}+\varepsilon_{i j}
$$

where $r_{i j}$ is the person $j$ 's stated likelihood of purchasing the ith tester, $x_{i l}$, is the level of the 1 th attribute of the ith tester, $\beta_{l j}$ is the regression weight associated with the 1 th attribute, $\varepsilon_{i j}$ is an error term, and $u_{i j}=\sum \beta_{l j} x_{i l}$ is the predicted utility of the ith tester to person $j$. A logit regression was used because it produces estimates that fall within the same 0- to 100-point range as the input data (like a logically consistent market share model) and is related to the BTL model [12], This combination of estimation and prediction methods was chosen because it was able to produce good predictions versus a range of other approaches in one comparison [27] and due to a managerial desire to produce individual-level utility estimates. Other approaches are possible, in particular, one may choose to use choice-based conjoint analysis [16, 17], which offers a better way to model the decision to not purchase any of the alternatives.

In sum, this procedure takes the following steps:

1. Estimate $\beta_{l j}$ for all individuals; determine $\mathrm{P}, \mathrm{F}$, and $\mathrm{C}$ vectors and $\mathrm{S}$.

2. Choose competitive product descriptions.

3. Choose $X_{j}$.

4. Forecast each person's $P C_{i j}$; sum to get $M S_{i}$.

5. Calculate Profit

6. Repeat steps 3-6 using different $X_{i} s$.

With $<100,000$ possible combinations in this application, complete enumeration was a feasible solution method. Green and Krieger [7] stated that complete enumeration was feasible with up to 1 million possible alternatives in 1991. That limit is undoubtedly higher today. 
With platforms, the following function is maximized:

$$
\text { Profit }_{i}=\sum_{m}\left(S_{m} M S_{m i}\left(P R_{m i}-V C_{m i}\right)\right)-T F C_{i} .
$$

Profit $t_{i}$ is the total profit for a platform and derivative launched into each of $M(m=1, \ldots, M)$ markets. Total profit is the sum of the profits from each of the markets. $T F C_{i}$ is the total fixed cost of the platform and derivative products launched from it. The same procedural steps are followed. In this case, the platform part of the product is held constant across all products on any given iteration. In our illustration, $M=2$. However, much larger problems cam be solved in the same manner. Also, it is possible to incorporate longitudinal effects with an equation similar to Equation 2 if necessary. 